\title{
TEXTURE DEVELOPMENT IN GYPSUM DURING CRYSTALLISATION
}

\author{
D. VOGEL, H. JACOBI AND H. FOLLNER \\ Institut für Mineralogie und Mineralische Rohstoffe, Technische Universität, \\ Clausthal-Zellerfeld, Germany \\ H. KLEIN \\ Institut für Metallkunde und Metallphysik, Technische Universität, Clausthal- \\ Zellerfeld, Germany
}

(Received 12 July 1994)

\begin{abstract}
Gypsum was set on polyethylene foil of different origin and on cellophane foil. Experiments were also carried out in an electric field (5-25 kV direct-current). In all cases (especially in the electric field) (010) textures developed on the contact surfaces and were overlapped by a (12i) texture. Brinell hardness tests show a greater hardness of the contact areas than those of the upper sides of the samples. Those samples set in an electric field yielded, partly, greater differences. The values, however, diverge greatly.
\end{abstract}

KEY WORDS: Gypsum, texture, hardness test.

\section{INTRODUCTION}

Gypsum is, technically seen, a material with various uses. The building industry and dental medicine use gypsum as moulding and impression material. The recrystallisation of gypsum takes place, normally, over the semihydrate which is won from natural deposits or synthetic gypsum.

$\mathrm{CaSO}_{4} \cdot 2 \mathrm{H}_{2} \mathrm{O}$ crystallizes in the space group I $2 / \mathrm{a}$ with the lattice constants $a=5,679$, $b=15,202, c=6,522 \AA, \beta=118,43^{\circ}$ and $Z=4$ (Pedersen, Semmingsen, 1982). The structure contains double layers parallel (010) consisting of calcium and sulphate ions which are separated by single layers containing water molecules. On crystals grown freely, the face forms $\{010\},\{12 \overline{1}\},\{01 \overline{1}\}$ and $\{110\}$ were observed.

In dental medicine, gypsum is used as a moulding material for the production of artificial dentures (Sondermann, Zimmermann, Lehmann, 1988; Sondermann et al., 1989; Allmann et al., 1991; Jepsen et al., 1992). The most important factor concerning the properties of dental plaster forms is that of hardness of the surface. Different mould materials are used for the production of moulds. The hardness of the surface depends firstly on the nature of the material. Secondly, the hardness of the model surface is determined, to a large extent, by the crystallisation of gypsum on the surface. The texture density, content of $\mathrm{CaSO}_{4} \cdot \mathrm{xH}_{2} \mathrm{O}(\mathrm{x} \leq 1)$ and the anisotropy of the crystals are of importance. This effect is overlapped by possible crystalline efflorescence because 
of additives to the gypsum causing hardness of the surface to increase or decrease depending on the additives (with $\mathrm{K}_{2} \mathrm{SO}_{4}$-additives, for example, syngenite $\left(\mathrm{K}_{2} \mathrm{Ca}\left(\mathrm{SO}_{4}\right)_{2} \cdot \mathrm{nH}_{2} \mathrm{O}\right)$ was identified). Further, it was shown that hardness depends on the polarity of the moulding material.

These experiments were the starting point of an investigation of the surface texture properties of polycrystalline gypsum which was set on various materials (Girlich, 1992; Girlich et al., 1993). The following contact materials were used: - plexiglass, selenite, aluminium foil respectively cling foil (both normal household products) and alginate impression material. With the latter two contact materials gypsum samples were made with the addition of $0.2 \%$ citric acid. As shown on SEM photographs, the shape and intergrowth of crystals are dependent on the contact materials and the additive. In all cases, (010) fibre textures, developed in a surface layer of about $250 \mu \mathrm{m}$, were partly overlapped by $(12 \overline{1})$ textures. The Brinell hardness of contact planes of samples hardened on plexiglass and alginate impression material is greater than that of the upper sides. With cling foil it is vice versa. The samples with added citric acid show the expected lower hardness.

The following investigation gives the results of experiments with different foils made of polyethylene and cellulose as contact materials. Furthermore, the influence of an electric field generated by direct current on the crytallisation behaviour of gypsum was investigated (Vogel, 1994).

\section{TEXTURE ANALYSIS IN POLYCRYSTALLINE GYPSUM}

Samples of polycrystalline gypsum were produced by the following method: $150 \mathrm{~g}$ semihydrate ( $\beta$-semihydrate from the firm FLUKA) was dispersed, by hand, in $500 \mathrm{ml}$ of water and afterward homogenised with an electric mixer for three minutes. The gypsum paste was poured into sample vessels (for texture, respectively hardness measurements: radius $25 \mathrm{~mm}$ resp. $10 \mathrm{~cm}$, height $5 \mathrm{~mm}$ resp. $5 \mathrm{~cm}$ ) and after hardening 24 hours at room temperature they were put into a drying cupboard for another 24 hours at a temperature of $45^{\circ} \mathrm{C}$.

The contact materials used were normal cling foil made of polyethylene from Melitta (M), Alexia (A) and Folia (F) with a thickness of $0.01 \mathrm{~mm}$, a foil (X) of unknown origin with a thickness of $0.2 \mathrm{~mm}$ and a cellophane foil (Z). Apart from the normal setting procedure of gypsum on the different foils, the influence of an electric field generated by direct current $(5-25 \mathrm{kV})$ on this process was examined. The contact area of the sample was in contact with one of the condensator plates which was poled negative, but in a second investigation was poled positive.

SEM photographs of all contact areas show well-developed crystals with, whichever foil material used, partly needle-like, partly prismatic habitus and are oriented preferentially parallel to the sample surface. As a rule, under the influence of the electric field, finer needles appear which are matted together with greater density (Figure 1).

With the help of the X-ray phase analysis, the semihydrate could not be found in any of the cases. Small quantities of anhydrite II originate, obviously, from the semihydrate. In the near-surface areas of samples set in the electric field, much greater concentrations of anhydrite II were found than in the middle areas. The part of anhydrite II in the near-surface area facing the positive side of the condensator plate was always greater than in the part facing the negative pole. The cause of origin of anhydrite II has not been clarified. It is not to be excluded, that a concentration of anhydrite II resulted from wandering particles. 
(a)

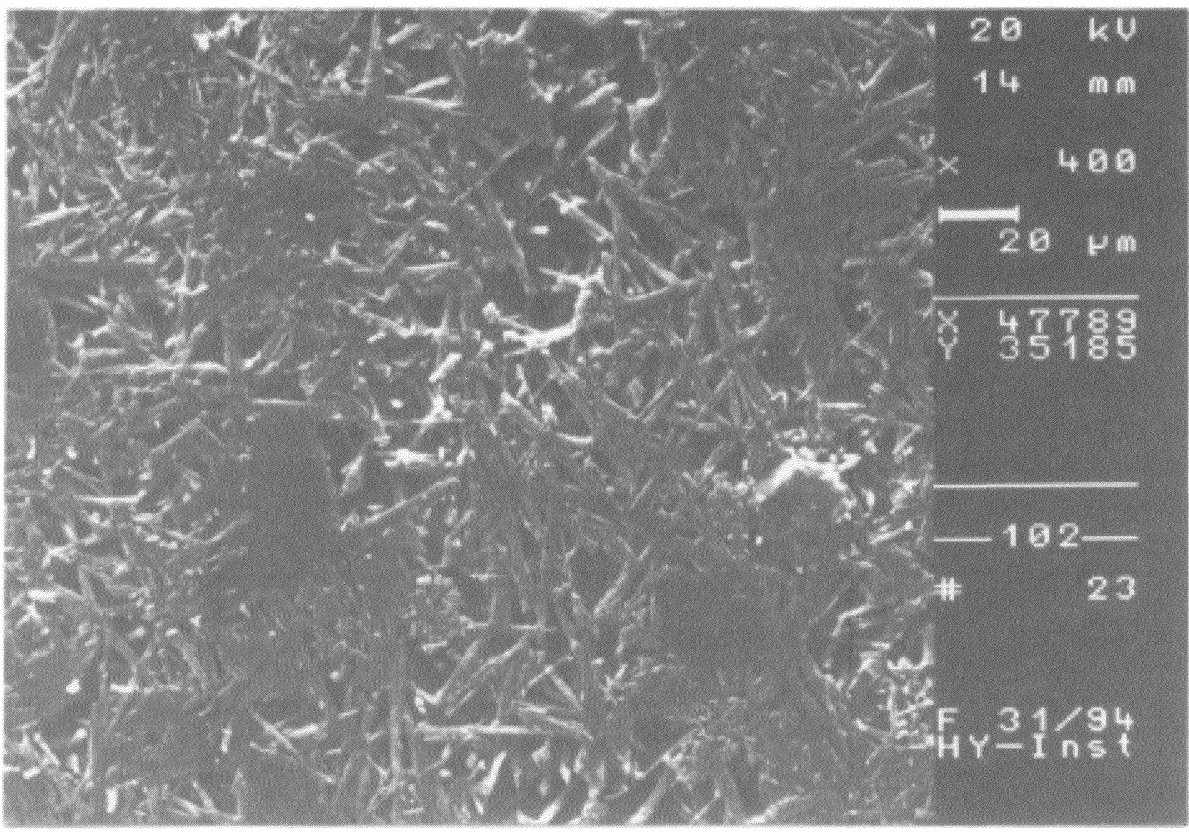

(b)

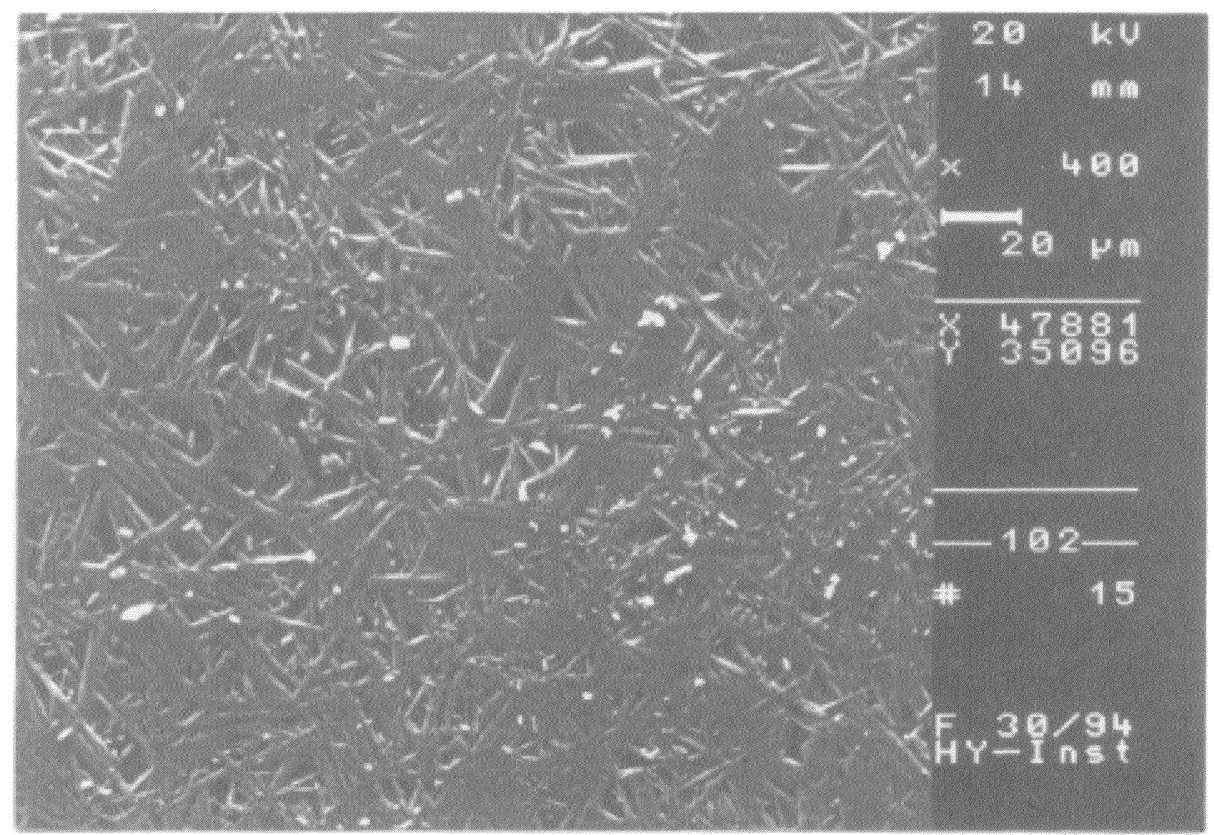

Figure 1 SEM photographs of the contact surfaces of samples hardened on Melitta (M) cling foil (a) without and (b) in an electric field generated by $25 \mathrm{kV}$ direct current. 
For texture examination the $(020)$ and $(12 \overline{1})$ pole figures of all samples were measured. Figures $2 a-d$ show one-dimensional sections of the diagrams of samples which were hardened without resp. with electric field influence. In the second case the contact areas faced the negative condensator plate. Between the diagrams obtained after pole changing of the electric field and those in Figure $2 c$ and $d$ are insignificant differences so that a presentation of the pole figures could be dispensed with. Deducting from the diagrams qualitatively is the fact that a (010) fibre texture is more or less overlapped by a (12 $\overline{1})$ texture. The $(020)$ and $(12 \overline{1})$ pole figures of a freely grown upper side only indicate a poor developed (010) texture (Figures 2a, b). This probably has its origin in the smoothing of the sample surface after filling the form. At the GKSS research centre in Geesthacht, a (020) pole figure measured by neutron diffraction on a sample body of $12 \mathrm{~mm}$ diameter and $12 \mathrm{~mm}$ height, shows that the (010)-texture is apparently not continued into the interior of the sample.

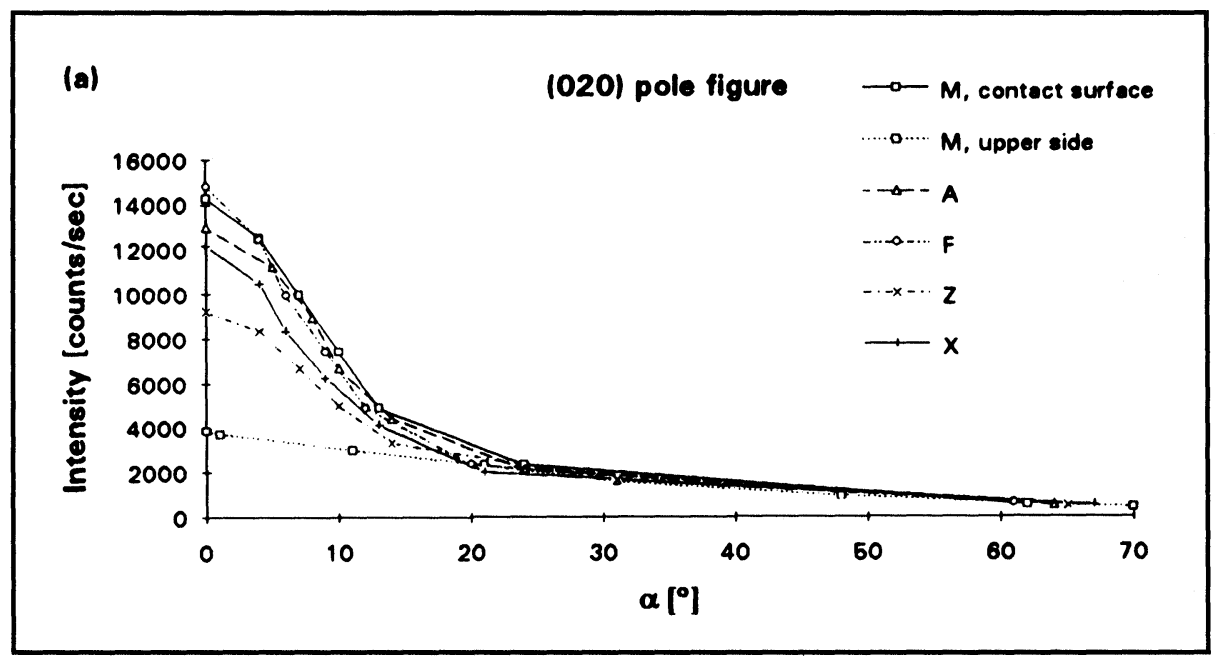

(b)

(12-1) pole figure

$\longrightarrow$ M, contect surface

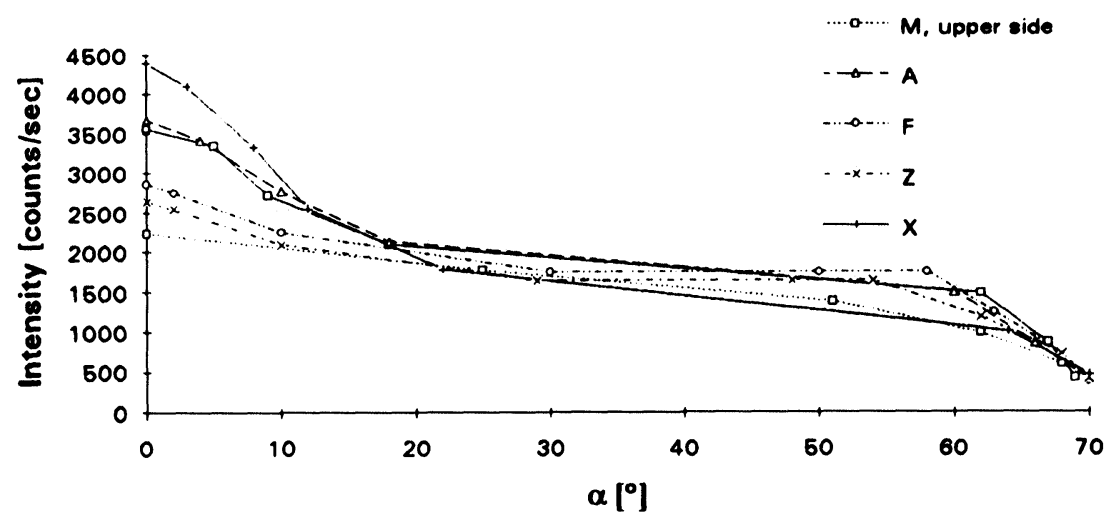



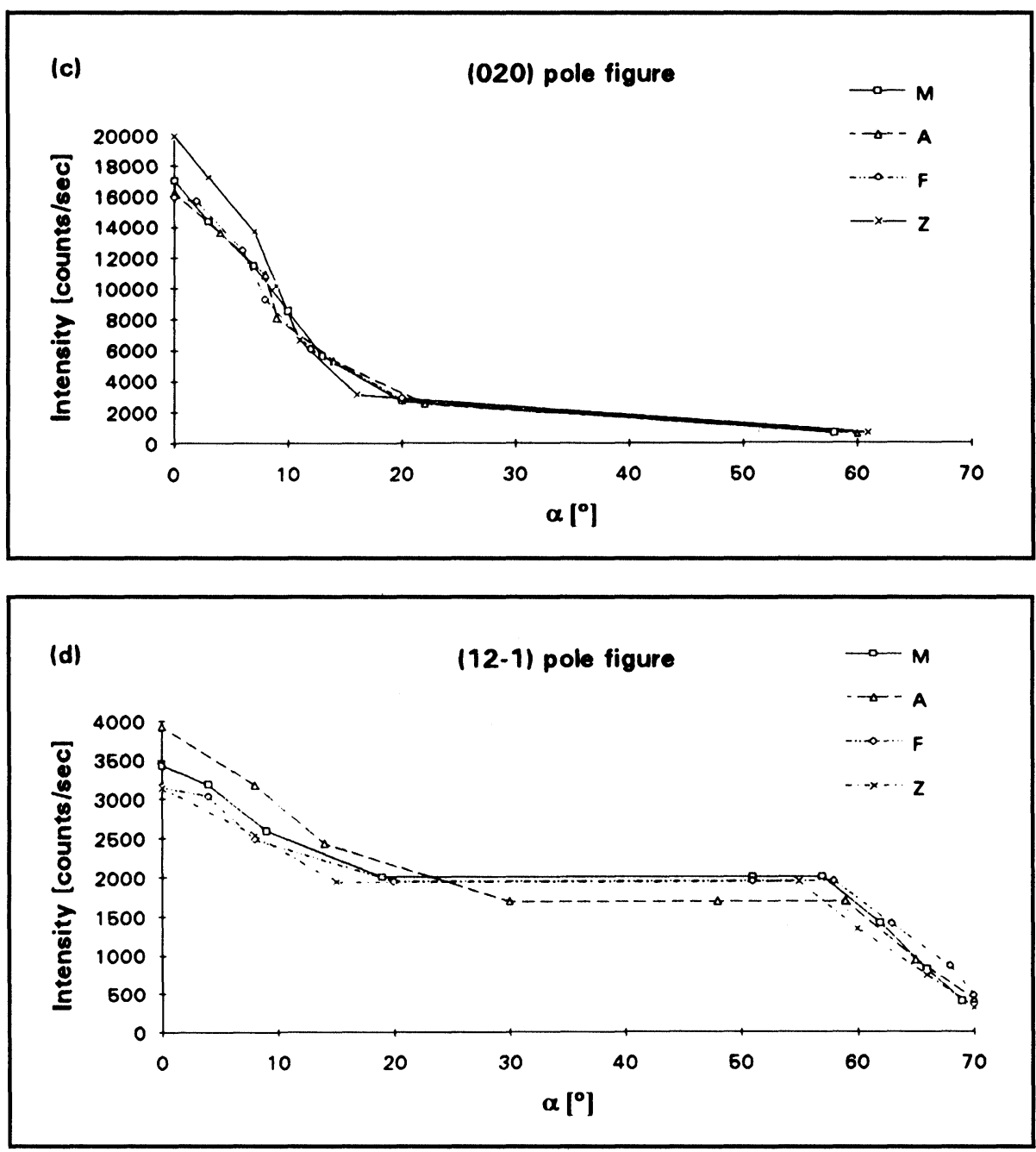

Figure 2 One-dimensional sections through the (020) and (12 $\overline{1})$ pole figures of gypsum samples hardened on polyethylene cling foils (M (Melitta), A (Alexia), F (Folia), X (of unknown origin; thickness: $0.2 \mathrm{~mm})$ ) and on cellophane foil $(\mathrm{Z})((\mathrm{a})$, (b) without and (c), (d) in an electric field generated by $25 \mathrm{kV}$ direct voltage; distance of the condensator plates: $10 \mathrm{~cm}$ ). With exception of sample $M$ pole figures are measured only on the contact surfaces.

\section{BRINELL HARDNESS}

The Brinell hardness of the sample surface was determined by an Erichsen- 462 E4 universal testing machine. A steel ball with a diameter of $8 \mathrm{~mm}$ was used as the indentation body and was indented $3 \mathrm{~mm}$ at a feeding rate of $2 \mathrm{~mm} / \mathrm{min}$. On both sides of the gypsum cylinders with a diameter of $10 \mathrm{~cm}$ and a height of $5 \mathrm{~cm}$ three measurements were taken which were then averaged. In Figure 3 the deviations in terms of percentage are related to the average hardness values of the contact surfaces and of the upper sides. 

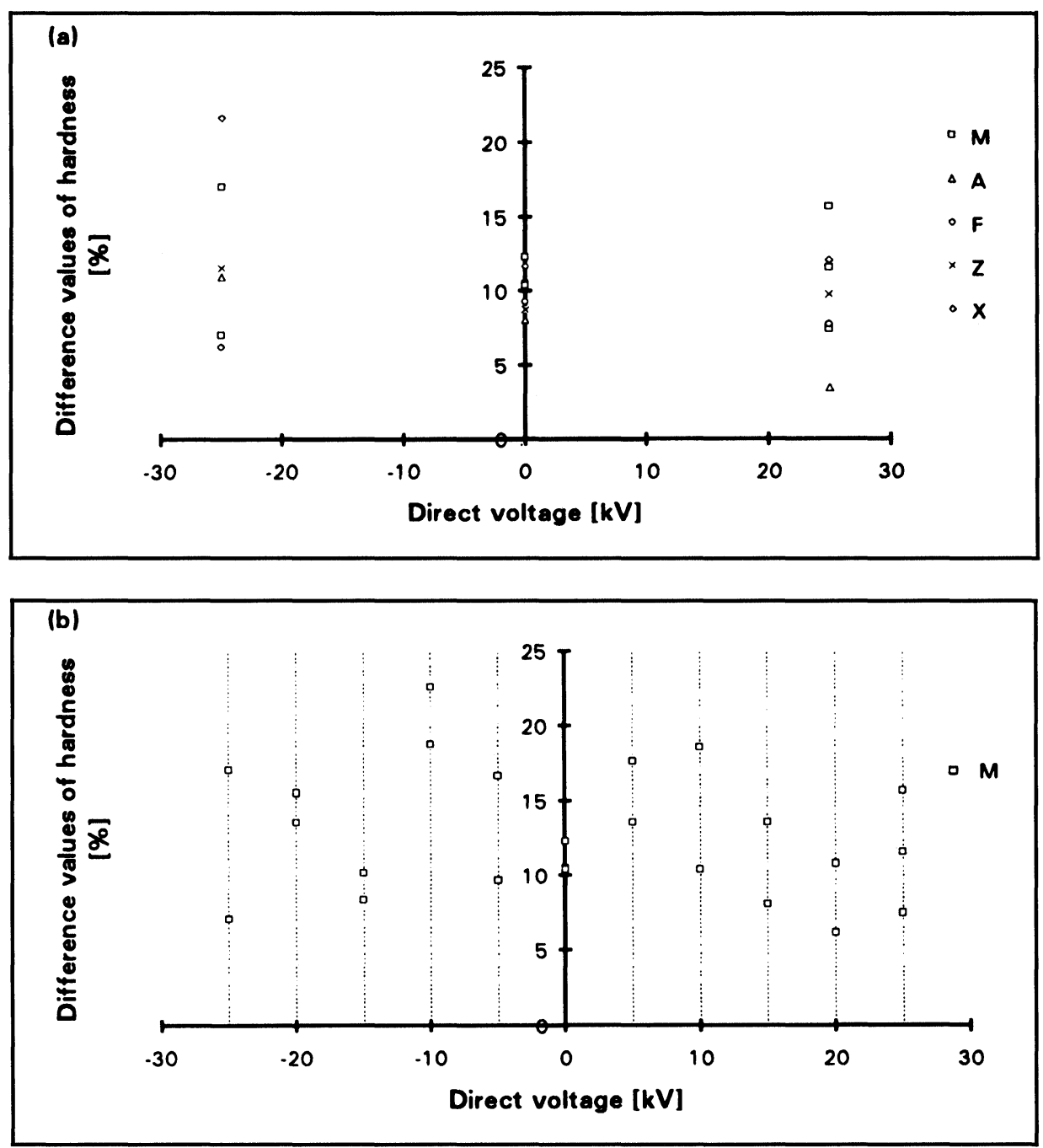

Figure 3(a), (b) Brinell tests on the contact surfaces and the upper sides of gypsum cylinders (diameter: $10 \mathrm{~cm}$, height: $5 \mathrm{~cm}$ ). The hardening took place on polyethylene cling foils (M (Melitta), A (Alexia), F (Folia), X (of unknown origin; thickness: $0.2 \mathrm{~mm}$ )) and on a cellophane foil (Z) in presence or absence of electric fields. The electric fields were generated by direct voltage (5-25 kV; negative and positive voltage numbers: The contact surfaces of the samples pointed towards the negative and the positive electric pole, respectively). The procentual values of hardness differences are related to the average of hardness values on the contact surfaces and on the upper sides. In (b) the values of $\mathrm{M}$ from (a) at 0 and $\pm 25 \mathrm{kV}$ are taken additionally.

Contrary to the results of Girlich et al. (1993) the contact surfaces hardened on all foils used in this investigation show a greater hardness than that of the upper sides. The previous result was confirmed after remeasuring the still-existant sample bodies. The origin of the foil (also a normal household product) is not known. As seen in Figure $3 \mathrm{a}$, with regard to different foils, there is no difference in the degree of hardness of samples if set without the effect of an electric field. The values of samples 
set in an electric field diverge greatly and are partly much bigger than those in the previous experiments. In a second series of experiments the effect of the amount of voltage was investigated (Figure $3 \mathrm{~b}$ ). A dependence of hardness values on the amount of applied voltage was not observed. Here, too, values diverge greatly. The statistic is not big enough for secure evidence.

\section{CONCLUSIONS}

The connection between the formation of $(010)$ textures and surface hardness is not strictly confirmed from this investigation. All samples which crystallized on the different contact materials developed surface textures. This is independent of the fact whether the setting process was with or without the effect of an electric field. The fluctuations of hardness in samples hardened in the electric field is incomprehensible as they were set on the same material. The differences in hardness which resulted in electric fields of different voltages are inexplainable. The aim of further investigations, however, has to be the examination of relationships in the interior of the samples.

\section{Acknowledgements}

Thanks are due to Dipl.-Ing. W. Unckenbold (Institut für Technische Mechanik der TU Clausthal) for his help in taking hardness tests. The authors express their gratitude to Dr. H.-G. Brokmeyer (GKSS-Forschungszentrum Geesthacht) for his assistance in carrying out neutron diffraction measurements.

\section{References}

1. Allmann, R., Dittrich, W., Lehmann, K. M. and Sondermann, U. (1991). Zeitschrift für Kristallographie, Supplement Issue 3, 6.

2. Girlich, I. (1992). Orientierungsbestimmung in Mikrobereichen von Gips und Untersuchungen zur Gefügecharakterisierung. Diplomarbeit, Leipzig.

3. Girlich, I., Wagner, G., Paufler, P., Leuner, S. and Follner, H. (1993). Neues Jahrbuch für Mineralogie, Monatshefte, 312-323.

4. Jepsen, H., Lehmann, K. M., Schwerte, Ch. and Sondermann, U. (1992). Zeitschrift für Kristallographie, Supplement Issue 5, 119.

5. Pedersen, B. F. and Semmingsen, D. (1982). Acta Crystallographica, B38, 1074-1077.

6. Sondermann, U., Richter, F. W., Macholdt, H. and Allmann, R. (1989). Zeitschrift für Kristallographie, 186, 278.

7. Sondermann, U., Zimmermann, A. and Lehmann, K. M. (1988). Zeitschrift für Kristallographie, 182, 248.

8. Vogel, D. (1994). Zum Kristallisationsverhalten von polykristallinem Gips. Diplomarbeit, Clausthal-Zellerfeld. 